the classroom where children participate in ALB. Classroom environments are different for girls and boys. Numerous studies have shown that teachers do. not interact in the same way with girls and boys. Boys interact more with teachers than do girls, girls have many more days in which they do not interact at all with the teacher, boys initiate more contacts with teachers than do girls, and teachers initiate more contacts with boys. Boys receive more discipline contacts, and more praise. Teachers accept wrong or poor answers more often from boys. While teachers respond more frequently to requests for help from boys than from girls, teachers tend to criticize girls more than boys for the academic quality of their work. Teachers interact more with high achieving boys than with high achieving girls and interact less with girls who have high confidence in learning mathematics than with high confidence boys. High confidence boys interact at higher cognitive levels with their teachers more often than high confidence girls (see Fennema and Peterson, in press, for a more complete review of classroom studies). It appears reasonable to assume that differential classroom experiences influence the development of one's internal motivational beliefs, and/or directly influence the participation in ALB.

The learning of mathematics, particularly the skills required to perform high level tasks, does not occur quickly and at one point in time. Rather, these skills are developed over a long period of years by participating many times in the activities necessary for performing the high level tasks. Indeed, a very circular path is required. One learns to do high level tasks by choosing, persisting, and succeeding at high level tasks. These ALB serve as the mediators between classroom processes, internal motivational beliefs, and achievement in mathematics. If the model proposed here has validity, it will provide a partial explanation of why females are not achieving equity in mathematics education.

\title{
MODEL OF STUDENTS' MATHEMATICS ENROLLMENT DECISIONS
}

\section{JACQUELYNNE ECCLES*}

All too frequently, females choose not to lake more advanced mathematics courses (see Eccles, 1984. Meece et al., 1982). While many researchers have expressed an interest in this problem, especially in the effects of attitudes on achievement and course selection in mathematics, their research has been seriously limited by a number of methodological and conceptual shortcomings. Of major importance is the lack of an integrative theoretical framework to

* University of Michigan, Ann Arbor, U.S.A. 
guide the selection of a comprehensive set of variables for study and a definition of these variables in terms of their relevant dimensions. In response to this shortcoming, this paper briefly summarizes a theoretical model for studying students' choices and decisions (see Eccles et al. (1984), for fuller discussion).

Building upon general expectancy/value theories of achievement (Atkinson, 1964; Crandall, 1969; Lewin, 1938; Weiner, 1974), the framework proposed by Eccles et al. (1983) links the decision to enroll in mathematics to two specific cognitive constructs: expectancy for success and the subjective value of the task for the individual. Individual differences on these two cognitive constructs are attributed to variations in aptitude and performance, on socialization experiences, and on students' current and future goals.

In line with cognitive approaches to achievement motivation, the effects of achievement and experience are assumed to be mediated by a student's interpretation of these events in light of cultural influences and a fairly stable perception of oneself. Therefore, as shown in Figure 1, achievement expectancies and values are hypothesized to be influenced by students' perceptions of their own abilities, personal needs, and future goals, and by their perceptions of a set of task characteristics inherent in various achievement tasks. Individual differences on these variables are assumed to result from students' perceptions of socializers' beliefs and behaviors, students' causal attributions for their own successes and failures, students' perceptions of role-appropriate behaviors and goals, and previous experiences with similar achievement situations.

The model stresses the interactive qualities of expectancy for success and

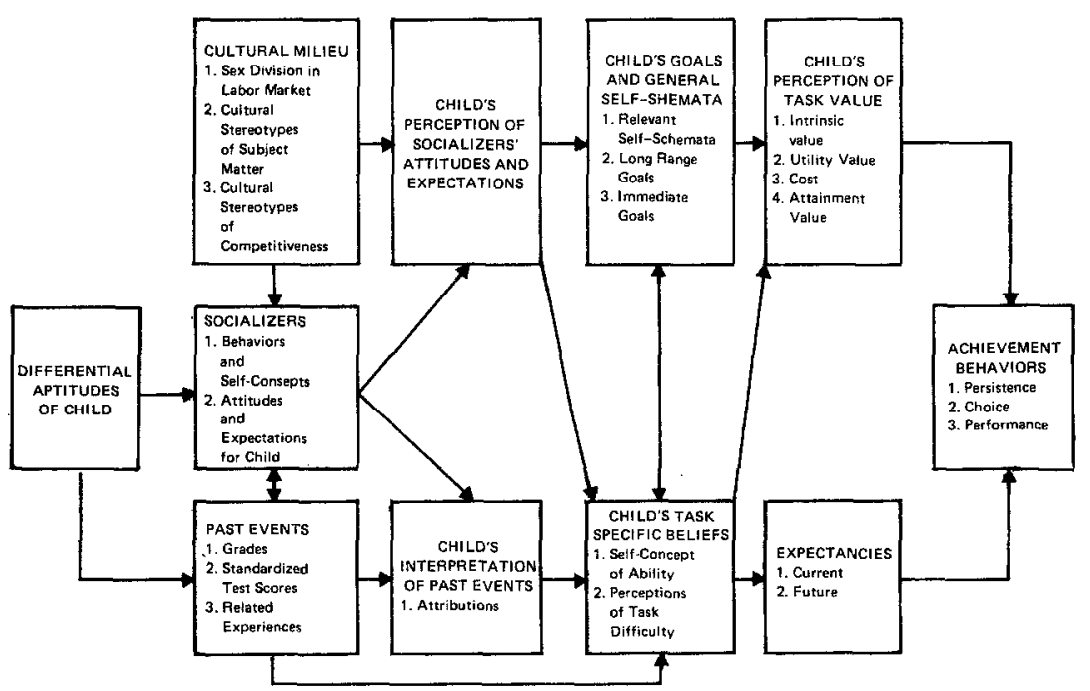

Fig. 1. 
subjective task value. Work within the general expectancy/value framework has tended, over the last decade, to focus primarily on variables that are presumed to be related to students' expectations for success. Individual variations in achievement have been attributed to differences in such constructs as confidence in one's abilities. Much of the research on sex differences in mathematics participation has embraced this same orientation. Too little attention has been paid to the impact of the subjective value of mathematics to the individual on students' decisions. This model clearly focuses attention on the importance of subjective value. Our own research has confirmed the importance of subjective task values as a critical mediator of sex differences in mathematics enrollment (see Eccles et al., 1984). Finally, the model specifies the range of factors that can influence subjective value, including sex-role identity, sex-typing of mathematics and other alternative courses, as well as one's affective experiences in mathematics classrooms and the adequacy of one's career counseling in school and at home.

The model also places the decision to enroll in math courses in the context of a complex social environment which confronts students with a wide variety of choices. These decisions are assumed to be guided by a set of core values such as achievement needs, competency needs, and sex role values, and by more utilitarian values such as the importance of mathematics courses for future goals. Thus, if a girl likes math, but feels that the amount of effort it will take to do well is not worthwhile because it decreases the time she will have available for more preferred activities (i.e., activities more consistent with her personal values), she will be less likely to continue taking mathematics. Similarly, if a girl stereotypes mathematics or careers involving competency in mathematics as masculine and not consistent with her own sex role values, she will be less likely to value mathematics learning and less likely to continue her mathematical studies, especially if she does not expect to do well.

Finally, the model clearly stresses the importance of modifiable determinants of course selection and achievement in mathematics. While the model does not rule out the possibility of biological explanations for sex differences in mathematics achievement it is assumed that a student's ultimate decision regarding pursuit of mathematics training is more likely to be a consequence of the student's interpretation of reality rather than reality itself. Analyzing the problem from this perspective helps clarify some of the inconsistencies found in the mathematics achicvement litcrature. For example, past research has shown that girls do as well as boys in mathematics classes throughout their formative years, yet they do not expect to do as well and are less likely to go on in mathematics. The extent to which boys and girls differ in their interpretation of achievement outcomes because of the differential information they 
receive from their social environment could, in fact, account for this apparent paradox. The subjective meaning individuals attach to math is mediated by a variety of psychological and social factors such as the causal attribution made for their past mathematics performance, the input of socializers, perceptions of the demands inherent in mathematics as a subject area, and perceptions of their own needs, values, and role identity. Each of these factors is assumed to play a role in shaping students' confidence in their mathematics abilities, their expectations regarding future success, the subjective value they attach to mathematics, and ultimately students' decisions regarding enrollment in mathematics courses.

Many of the theoretical predictions generated by this model have not been explained. However, much of the existing research clearly points out the importance of several of the constructs. The importance of other constructs and the causal relations specified by the model have not been tested. In an effort to test some of these predictions, Eccles and her colleagues are conducting a large-scale, multi-faceted longitudinal study of sex differences in math participation. Preliminary results of this study are reviewed in Eccles (1984) and Eccles et al. (1983).

\title{
PRELIMINARY NOTES ON A THEORY OF INFORMAL BARRIERS FOR WOMEN IN MATHEMATICS
}

\author{
DAVID R. MAINES*
}

This paper examines the nature of informal barriers for women who enter and attempt to forge careers in mathematics. It takes the position that the existing literature on women in male dominated professions suffers from an overly dualistic conception of such barriers. An alternative theory is proposed which draws from interactionist sociology and anthropology and which is grounded in a dialectical and interpretative ontological view of society (see Geertz, 1973; Mead, 1934; Denzin, 1982).

\section{Historical and Conceptual Considerations}

There is no denying that the historical record of women who became mathematicians is one of their dealing with extremely oppressive legal, family, and organizational systems. While that oppression was primarily from the hands of men, it was not exclusively so because these women's mothers, sisters and

* University of Iowa, Iowa City, U.S.A. 